\title{
Effect of Capsaicin on the Barrier Functions of Porcine Intestinal Epithelial Cells (IPEC-J2)
}

\author{
Bernadette Espana $^{1}$, Delphine Le Guern ${ }^{1}$, Camille Rozier ${ }^{2}$ and Caroline Prouillac ${ }^{2 *}$ \\ ${ }^{1}$ Université de Lyon, VetAgro Sup, Marcy l'Etoile, France \\ ${ }^{2}$ ID4FEED SAS, Annecy, France \\ ${ }^{\star}$ Corresponding author: Caroline Prouillac, 1 avenue bourgelat 69280 Marcy l'Etoile, France; Email: caroline.prouillac@vetagro-sup.fr
}

Received: November 26, 2021; Accepted: December 09, 2021; Published: December 05, 2021

\begin{abstract}
Due to the antibiotic resistance context, it is becoming necessary to ensure the good health of farm animals while decreasing antibiotics prescription. The use of feed supplements is among these methods. These supplements improve animal performance and health by stimulating physiological processes, such as immune function and stress resistance. Capsaicinoids are derivatives produced by plants of the genus Capsicum and members of the vanilloid family. Capsaicin strengthens the immune system, has anti-inflammatory properties and limits oxidation and is known to improve the growth rate in pigs. The purpose of this study was to assess the permeability and transport characteristics of capsaicin in pig intestinal cells (IPEC-J2). We confirmed the absence of active transport of capsaicin and its derivatives with an impact on the intestinal epithelium resulting in an increase in permeability. This alteration of the permeability of the intestinal barrier is observed in another reference line, the Caco- 2 cell line. Then, we also investigated the modulation of the expression of transporters for multidrug resistance and tight junction protein by capsaicin. Prolonged exposure to low doses of capsaicin seems to be responsible for a modification of the expression of transport proteins. The results showed a significant increase on $P G P$ expression after $24 \mathrm{~h}$ of capsaicin exposure at $10 \mu \mathrm{M}$ and a slightly significant induction in the mRNA expression levels of MRP1 was observed after 24h. Despite the short exposure time (90 $\mathrm{min}), 10 \mu \mathrm{M}$ capsaicin exposure led to a slight induction of Occludin and Zo-1 mRNA expression.
\end{abstract}

Keywords: Intestinal absorption, In vitro model, Tight junctions, ABC transporters

\section{Introduction}

Antimicrobial drugs are currently used to treat or prevent bacterial infections in the livestock industry; in some countries they are also used for growth promotion in food animals. This widespread use of antimicrobials in particular in intensive livestock farming contributes to the emergence of antimicrobial resistance with significant public health implications. Prevalence of resistant bacteria in animals and humans seems to be correlated with the levels of antimicrobial use in animals [1-4]. In the future, predictions for global antibiotic use do not seem to be moving towards a decrease [5]. Alternative for use of antibiotic in food producing animals, especially intensive livestock (swine, poultry) represent an issue while preserving health and welfare of animals. Plant extracts or phytochemicals are one of the solutions being explored at the World Organization for Animal Health in Paris, France, December 12-15, 2016. Phytochemicals are natural bioactive compounds that are originated from plants and incorporated into animal feed to enhance productivity and healthy. Their role in the production of digestive secretions, nutrient absorption and modulation of gut microbiote and immunity are the main mechanisms suggested. Due to variation in the composition of plant extracts, it remains difficult to compare their efficiency. The composition and concentration of the bioactive compounds depend on the plant, parts of the plant, geographical origin, harvesting season, environmental factors, storage conditions, and processing techniques.
A wide variety of herbs and spices are used for this purpose [6,7]. Anethol, carvacrol, cinnamaldehyde, curcumin, eugenol, thymol and capsaicin are still the main constituents studied [8]. Capsaicin and dihydrocapsaicin are the main representative capsaicinoid derivatives and members of the vanilloid family. These molecules are produced by plants of the genus Capsicum, also known as chili pepper fruit. Capsaicin is responsible for the spicy taste and feelings of hotness. Its action is especially mediated by transient receptor potential vanilloid subfamily member 1 (TRPV1), a nonselective ligand-gated cation channel. Activation of this receptor is also mediated by other plant bioactives such as menthol [9] and leads to the opening of ion channels and the entry of cations such as $\mathrm{Na}^{+}$and $\mathrm{Ca}^{2+}$ into neurons. Dunshea et al. (2003) [10] demonstrated that capsaicinoids may improve the growth rate in pigs. Few studies have reported the same results [11] and one patent has been pending since 2008 [12]. More recently, the benefits of dietary supplementation with Capsicum oleoresin were demonstrated on heat stress on pig performance [13]. Previous studies indicate that capsaicin is rapidly absorbed from the stomach and intestine by a passive process, with a total absorption capacity between 50 and $90 \%$ in different rodent studies [14,15]. However, capsaicin causes structural changes in the Caco-2 cell monolayer by increasing epithelial permeability [16-18]. Capsaicin could inhibit and upregulate P-glycoprotein, which could influence the bioavailability of the P-gp substrate $[19,20]$. 
In the present study, we examined the effect of capsaicin on the IPEC-J2 cell line, a permanent nontransformed intestinal cell line isolated from the jejunum of neonatal unsuckled piglets. This cell line was chosen based on the use of capsaicin as feed additive in piglets before in vivo investigation. IPEC-J2 cells grew on permeable inserts and formed a polarized monolayer similar to Caco-2 cells [21]. This model is already used to investigate compounds having a negative effect on epithelial function [22] and monolayer permeability [21]. The purpose of this study was to assess the permeability and transport characteristics of capsaicin in IPEC-J2 cells. After characterization of the expression of transporters for multidrug resistance, we investigated the modulation of $\mathrm{ABC}$ transporters (P-gp, MRP1, MRP2, BCRP) and tight junction proteins by capsaicin.

\section{Materials and Methods}

\section{Chemicals}

A certified standard with high purity capsaicin (CAPS) was purchased from Sigma-Aldrich (St. Quentin Fallavier, France). Methanol and acetonitrile (MeCN) (HPLC gradient grade) used for the mobile phase were provided by VWR Chemicals (Fontenaysous-Bois, France). Water for HPLC was supplied by a demineralized water system from an aquadem (Veolia Water Technologies, Antony, France). Individual stock solutions at $1000 \mathrm{mg} \mathrm{L}-1$ were prepared in $\mathrm{MeCN}$, and a standard mixture with all analytes at $10 \mathrm{mg} \mathrm{L}^{-1}$ was prepared in $\mathrm{MeCN}$ and stored at $-18^{\circ} \mathrm{C}$.

\section{Cell Culture}

The IPEC-J2 line was obtained from Leibnitz Institute (DSMZ, Germany) and was used between passages 2 and 8 . The cell line was maintained in DMEM/F-12 medium supplemented with $10 \%$ fetal calf serum, $1 \%$ penicillin/streptomycin, and $1 \%$ insulin-transferrinselenium in a humidified atmosphere of $95 \%$ air and $5 \% \mathrm{CO}_{2}$ at $37^{\circ} \mathrm{C}$. Culture medium was changed three times a week. Cells were subcultured at $80 \%-100 \%$ confluency using trypsin-EDTA. The human colon adenocarcinoma cell line Caco-2 was obtained from the American Type Culture collection (ATCC $\mathrm{N}^{\circ} \mathrm{HTB} 37$ ). Cells were routinely maintained and grown in Dulbecco's modified Eagle's medium Glutamax containing 10\% heat-inactivated fetal calf serum, $1 \%$ nonessential amino acids, $5 \%$ penicillin $(100 \mathrm{U} / \mathrm{ml})$ and streptomycin $(100 \mathrm{mg} / \mathrm{ml})$ in a humidified atmosphere of $95 \%$ air and $5 \% \mathrm{CO}_{2}$ at $37^{\circ} \mathrm{C}$. For the transport studies, cells were seeded on polycarbonate membrane inserts $(0.4 \mu \mathrm{m}$ pore diameter, $30 \mathrm{~mm}$ diameter; Millipore, Dutscher, Denmark). Transepithelial electrical resistance (TEER) was checked every 5 days using a millicell ERS ohmmeter (Millipore, Molsheim, France). Apical (AP) and basolateral (BL) chamber volumes were maintained at 1.5 and $2 \mathrm{ml}$, respectively. Cells were used for transport experiments when TEER values were above $1000 \mathrm{Ohm} / \mathrm{cm}^{2}$ for IPEC-J2 cells and at days 21-22 postseeding for Caco-2 cells.

TEER was calculated from the following equation:

$$
T E E R=\left(T E E R_{\text {cell }}-T E E R_{\text {blank }}\right) \times A
$$

where TEER $_{\text {cell }}$ is the cell monolayer and polycarbonate porous membrane resistance, $\mathrm{TEER}_{\text {blank }}$ is the polycarbonate porous membrane resistance (without a cell monolayer), and $\mathrm{A}$ is the polycarbonate porous membrane surface area $\left(4.2 \mathrm{~cm}^{2}\right)$. Cell culture media and reagents were obtained from Fisher Scientific (Illkirch, France). Culture flasks and plates were purchased from Falcon (VWR International, Strasbourg, France).

\section{Cytotoxicity}

Cell cytotoxicity was assessed by the CCK- 8 assay (Sigma Aldrich, Saint Quentin Fallavier, France) according to the manufacturer's instructions. Cells were seeded in 96-well plates $\left(1.10^{5}\right.$ cells/well $)$ and maintained in a humidified atmosphere of $95 \%$ air and $5 \% \mathrm{CO}_{2}$ at $37^{\circ} \mathrm{C}$ until they reached $90 \%$ confluence. The IPEC J 2 cell line was exposed to capsaicin at concentrations ranging from $0.1 \mu \mathrm{M}$ to $1 \mathrm{mM}$. Two exposure times ( $24 \mathrm{~h}$ and $48 \mathrm{~h}$ ) were tested. Absorbance at 490 $\mathrm{nm}$ was read using a Multiskan Microplate reader.

\section{Instrumentation and Chromatographic Conditions}

The HPLC system consisted of an Agilent 1260 affinity II with a $100 \mu \mathrm{l}$ sample loop and a G7121B fluorescence detector at an excitation wavelength of $281 \mathrm{~nm}$ and emission of $312 \mathrm{~nm}$ (Agilent Technologies, les Ulis, France). Chromatography was performed using partial-loop injection of a $50 \mu \mathrm{l}$ sample on an ACE Excel 5 C18-PFP (150 x 4.6$5 \mu \mathrm{m}$ ) (VWR international Fontenay sous bois, France) at $40^{\circ} \mathrm{C}$. The mobile phase consisted of water (A) and acetonitrile (B). A flow rate of $1 \mathrm{ml} / \mathrm{min}$ was maintained, and capsaisinoids were eluted using the following program: 0-2 min isocratic hold 35\% B, 2-10 min linear gradient $35-65 \%$ B. The retention times were 9.9, 10.2 and $11.3 \mathrm{~min}$ for NDHC, CAPS, and DHC, respectively.

\section{Permeability Studies}

Cells seeded on membrane inserts were exposed to fluorescein $(2 \mu \mathrm{g} / \mathrm{ml})$ on the apical side. Fluorescein passage was evaluated in the basolateral compartment at 15,30, 45, and $60 \mathrm{~min}$. The chromatographic conditions for the quantification of fluorescein were as follows: VWR Lichrospher ${ }^{\circledR} \mathrm{C} 18$ column $(250 \mathrm{~mm}$ x $4.6 \mathrm{~mm}$ inner diameter, particle size $5 \mu \mathrm{m}$ ), mobile phase consisting of acetonitrile (A) and water (B) with a linear gradient from 20 to $65 \%$ of $\mathrm{A}$ in 4 $\mathrm{min}$. The flow rate was $1.0 \mathrm{ml} / \mathrm{min}$, the temperature of the column furnace was set at $40^{\circ} \mathrm{C}$, and the injection volume was $10 \mu \mathrm{l}$. The excitation wavelength of the fluorescence detector was set to $485 \mathrm{~nm}$, and the emission wavelength was set to $515 \mathrm{~nm}$. The method exhibited linearity in the range of 50 to $2000 \mathrm{ng} / \mathrm{ml}\left(\mathrm{r}^{2}=0.9938\right)$. Precision and accuracy were also adequate, with intra- and interdaily variations of up to $10 \%$. No interferences were noted, demonstrating the selectivity and specificity of the method.

\section{Transport Studies}

After transepithelial electrical resistance (TEER) measurement, cell monolayers were preincubated for $30 \mathrm{~min}$ at $37^{\circ} \mathrm{C}$ in Hank's balanced salt solution (HBSS). For transport studies, apical (AP) and basolateral $(\mathrm{BL})$ chamber volumes were maintained at 1.5 and $2 \mathrm{ml}$ HBSS, respectively. Transepithelial transport of capsaicin was assayed by adding $10 \mu \mathrm{M}$ capsaicin either to the apical or basolateral compartment and measured over $4 \mathrm{~h}$. The permeability of capsaicin 
was estimated by calculating the values of $P_{\text {app }}$ as follows:

$$
P a p p=\frac{d Q}{d t} \times \frac{1}{A \times C_{0}}
$$

where $A=$ membrane surface area $\left(4.2 \mathrm{~cm}^{2}\right), C_{0}=$ initial concentration in the donor compartment, and $\mathrm{d} Q / \mathrm{d} T=$ permeability rate in receiver solution [23], calculated using linear regression (Microsoft Excel function, Excel: PC 2010).

The efflux ratio is determined by the following equations:

Efflux ratio $=\frac{P a p p(B L-A P)}{P a p p(A P-B L)}$

where $P_{\text {app }}(\mathrm{BL}-\mathrm{AP})$ is $P_{\text {app }}$ in the secretory direction and $P_{\text {app }}(\mathrm{AP}-$ $\mathrm{BL})$ is $P_{\text {app }}$ in the absorptive direction.

\section{Total RNA Extraction and cDNA Synthesis}

Cells were collected in RNA protect cell buffer (Qiagen, Courtaboeuf France) and stored at $-20^{\circ} \mathrm{C}$ until total RNA extraction. Total cell RNA was isolated and purified with the NucleoSpin RNA plus kit (Macherey-Nagel, Hoerdt, France) according to the manufacturer's instructions. All extractions were performed with a genomic DNA elimination step. Total RNA was quantified with a Biodrop $\mu$ Lite spectrophotometer (Biochrom, UK). cDNA was synthesized by reverse transcription with the PrimeScript RT reagent Kit (TaKaRa Bio, Ozyme France) according to the manufacturer's protocol. Reverse transcription was carried out on $0.5 \mu \mathrm{g}$ to $1 \mu \mathrm{g}$ of total RNA.

\section{Quantitative Real-time PCR}

Real-time quantitative PCR was performed using a QTower3 thermal cycler (Analytik Jena, Deutschland) and Eurobiogreen Master mix (Eurobio, Courtaboeuf). The amount of cDNA was 20 ng. Primer concentrations were $200 \mathrm{nM}$. Primer sequences and product size are indicated in Table 1 . The thermal cycling comprised a PCR activation step for $3 \mathrm{~min}$ at $95^{\circ} \mathrm{C}$ and 40 cycles with denaturing step at $95^{\circ} \mathrm{C}$ for $5 \mathrm{~s}$, annealing step at $60^{\circ} \mathrm{C}(P G P, M R P 1, M R P 2, B C R P, G A P D H)$, $50^{\circ} \mathrm{C}$ (Occludin and Zonula occludens ZO-1) or $58^{\circ} \mathrm{C}$ (Claudin) for $30 \mathrm{~s}$, and an extending step lasting $30 \mathrm{~s}$ at $72^{\circ} \mathrm{C}$. Primer pair specificity was tested at the end of every run by melting curve analysis, and amplification specificity was confirmed by electrophoresis in a $2 \%$ agarose gel. PCR efficiencies were calculated for each gene, allowing efficiency-corrected comparative quantification (Pfaffl, 2001). The relative mRNA levels in each sample were normalized to the housekeeping gene glyceraldehyde-3-phosphate dehydrogenase $(G A P D H)$ and expressed relative to a control (untreated sample). Reactions are carried out in duplicate.

\section{Statistical Analysis}

All results are expressed as the mean $\pm S D(n=3)$. Pairwise comparisons were calculated by unpaired Student's t-tests (XLSTATPRO 2010). A $p$ value of $<0.05$ was considered statistically significant.

\section{Results}

\section{Cytotoxicity}

The results of the CCK- 8 assay revealed that IPEC-J2 cell viability was reduced in a time- and dose-dependent manner following capsaicin treatment (Figure 1). Compared with the vehicle $(0.1 \%$ ethanol) controls, following cell treatment with 1 to $1000 \mu \mathrm{M}$ capsaicin for $24 \mathrm{~h}$, cell viability was reduced from 102.06 \pm 9.83 to $36.98 \pm 4.00 \%$. The same results were observed at $48 \mathrm{~h}$ post treatment, with 1 to $500 \mu \mathrm{M}$ decreasing cell viability from $85.37 \pm 3.28$ to $21.13 \pm 1.22 \%$. Considering these results, capsaicin at concentrations greater than or equal to $10 \mu \mathrm{M}$ had a significant effect on cell viability at $48 \mathrm{~h}$.

Table 1: Sequence of primers used for real-time quantitative PCR.

\begin{tabular}{|c|c|c|c|}
\hline Gene & Primer sequence $\left(5^{\prime}-3^{\prime}\right)$ & Amplicon length (pb) & Accession number \\
\hline \multirow{2}{*}{ GAPDH } & FP: AGCAATGCCTCCTGTACCACCAACTG & \multirow{2}{*}{200} & \multirow{2}{*}{ AF017079 } \\
\hline & RP: GCAGCACCAGTAGAAGCAGGGATGAT & & \\
\hline \multirow{2}{*}{$P G P$} & FP: TTGGCTGGAAAAGTGCTAATTGACGG & \multirow{2}{*}{259} & \multirow{2}{*}{ AY 825267} \\
\hline & RP: GCTGCGTTCCTTTGTCTCCCACTCTG & & \\
\hline \multirow{2}{*}{ MRP1 } & FP: TTCCGCGCACTCGTGGTTCAGCTTAT & \multirow{2}{*}{112} & \multirow{2}{*}{ CF368015 } \\
\hline & RP: GGACCCGTTCAGCCAGTACTCAGAGG & & \\
\hline \multirow{2}{*}{$M R P 2$} & FP: TACGAGGTGACAGAGGGCGGTGACAA & \multirow{2}{*}{159} & \multirow{2}{*}{ DQ530510 } \\
\hline & RP: TTGGATGGTCGTCTGGATGAGGTGAT & & \\
\hline \multirow{2}{*}{$B C R P$} & FP: GGACAAAACTTCTGCCCGGGACTCAA & \multirow{2}{*}{178} & \multirow{2}{*}{ NM_214010 } \\
\hline & RP: TCAGGTAGGCGATCGTCAGGAAAATG & & \\
\hline \multirow{2}{*}{ Occludin } & FP: ATCAACAAAGGCAACTCT & \multirow{2}{*}{157} & \multirow{2}{*}{ XM_005672522.3 } \\
\hline & RP: GCAGCAGCCATGTACTCT & & \\
\hline \multirow{2}{*}{ Claudin-1 } & FP: GCAGCAGCTTCTTGCTTCTC & \multirow{2}{*}{664} & \multirow{2}{*}{ NM_001244539.1 } \\
\hline & RP: CTGGCATTGACTGGGGTCAT & & \\
\hline \multirow{2}{*}{$Z O-1$} & FP: GAGTTTGATAGTGGCGTT & \multirow{2}{*}{298} & \multirow{2}{*}{ NM_001244539.1 } \\
\hline & RP: GTGGGAGGATGCTGTTGT & & \\
\hline
\end{tabular}




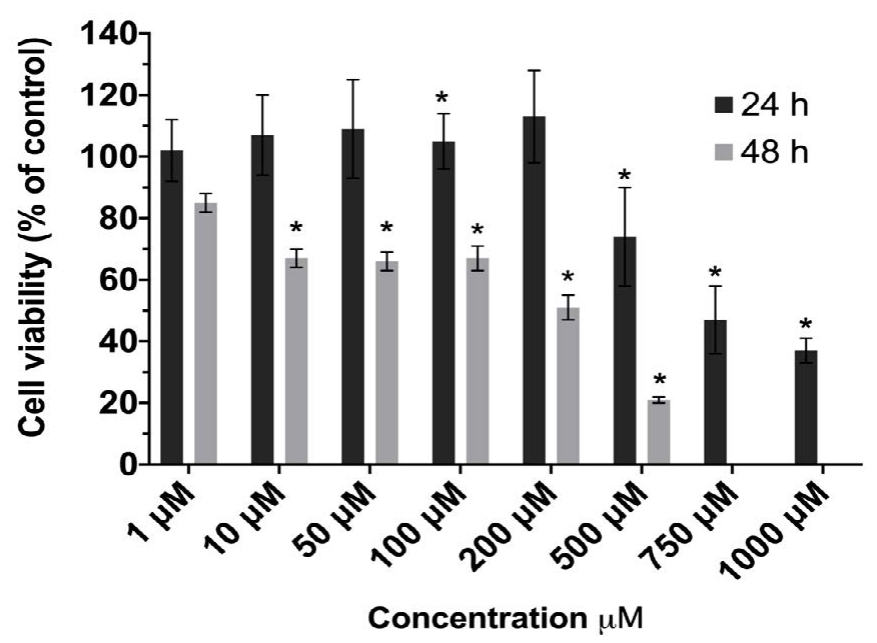

Figure 1: Effect of capsaicin on IPEC-J2 cell viability.

IPEC-J2 cell monolayers were exposed to capsaicin $(1-1000 \mu \mathrm{M})$ for $24 \mathrm{hrs}$ (dark gray) and 48 hrs (light gray). Data are means \pm S.D. $(n=8)$ expressed as $\%$ of control response. Statistically significantly different from control cell monolayers, ${ }^{*} p<0.05$.

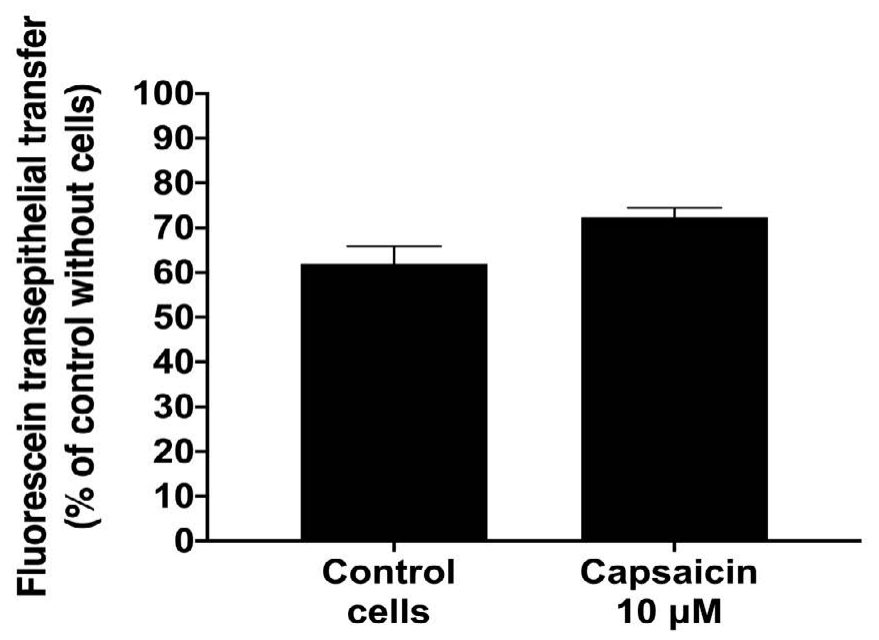

Figure 2: Effect of capsaicin on monolayer permeability to fluorescein.

Data are expressed as the mean \pm S.D. $(n=3)$. Statistically different from control cell monolayers, ${ }^{*} p<0.05$.

\section{Permeability Studies}

To evaluate the impairment of barrier function by capsaicin, we examined the flux of fluorescein across an IPEC-J2 monolayer (Figure 2). Untreated IPEC-J2 monolayers exhibited high paracellular passage in addition to a TEER value above $>1000 \mathrm{Ohm} / \mathrm{cm}^{2}$. Upon treatment with $10 \mu \mathrm{M}$ capsaicin for $90 \mathrm{~min}$, monolayer permeability significantly increased up to $70 \%$ of the control without cells (Table 2).

\section{Transport Studies}

The kinetics of capsaicin were investigated by performing transepithelial transport studies at increasing concentrations. The AP-BL and BL-AP efflux of $10 \mu \mathrm{M}$ capsaicin through IPEC-J2 and Caco-2 cell monolayers was measured for $2 \mathrm{~h}$. As shown in Table 1 , transepithelial transfer of capsaicin was quite rapid, with high transepithelial permeability. Bidirectional transport is not mediated by ATP-dependent transport systems: no difference was observed between AP-BL and BL-AP transfers.
Table 2: Apparent permeability coefficient (Papp x $10^{-5} \mathrm{~cm} / \mathrm{s}$ ) and net efflux of capsaicin transport across IPEC-J2 and Caco- 2 cell monolayers. Data are expressed as the mean \pm S.D. $(n=3)$.

\begin{tabular}{|l|c|c|c|c|}
\hline & & \multicolumn{2}{|c|}{ Papp $\left(\times \mathbf{1 0}^{-5} \mathbf{c m} / \mathbf{s}\right)$} & Ratio \\
\hline & & $\mathbf{A P} \rightarrow \mathbf{B L}$ & $\mathbf{B L} \rightarrow \mathbf{A P}$ & $\mathbf{B L} \rightarrow \mathbf{A P} / \mathbf{A P} \rightarrow \mathbf{B L}$ \\
\hline \multirow{2}{*}{ IPEC-J2 } & Capsaicin $1 \mu \mathrm{M}$ & $4.71 \pm 0.91$ & $6.27 \pm 0.11$ & $1.12 \pm 0.33$ \\
\cline { 2 - 5 } & Capsaicin $10 \mu \mathrm{M}$ & $5.92 \pm 1.93$ & $6.57 \pm 1.66$ & $1.13 \pm 0.19$ \\
\hline Caco-2 & Capsaicin $10 \mu \mathrm{M}$ & $4.21 \pm 1.04$ & $3.92 \pm 0.73$ & $0.94 \pm 0.007$ \\
\hline
\end{tabular}

\section{ABC Transporter mRNA Expression}

As the expression of $\mathrm{ABC}$ transporters has not been described in IPEC-J2 cells, we investigated the basal expression of these proteins at the mRNA level and explored the effect of the cell polarization process. Relative expression of ABC transporter mRNA in IPEC-J2 cells demonstrated a high level of MRP2 and BCRP mRNA expression compared to other ABC transporters (Figure 3A). Significant increases in MRP2 and BCRP mRNA expression were observed in differentiated cells grown on permeable support. As capsaicin could influence the expression level of $A B C$ transporters, we studied the effect of 1 and $10 \mu \mathrm{M}$ capsaicin on $\mathrm{ABC}$ transporter mRNA expression in IPEC-J2 cells after $24 \mathrm{~h}$ and $48 \mathrm{~h}$ of exposure (Figure $3 \mathrm{~B}$ ). The results showed a significant effect on $\mathrm{ABC}$ transporter expression after $24 \mathrm{~h}$ of capsaicin exposure at $10 \mu \mathrm{M}$. A slightly significant induction in the mRNA expression levels of MRP1 was observed.

\section{Tight Junction Proteins mRNA Expression}

IPEC-J2 cells were exposed to capsaicin to determine whether there was any alteration in the tight junction proteins Claudin-1, Occludin, and Zo-1 (Figure 3C). Tight junctions are known to regulate the intestinal epithelial paracellular pathway and play a role in intestinal permeability. The exposure times correspond to those of the kinetic and fluorescein permeability tests. Despite the short exposure time, capsaicin exposure led to a slight induction of Occludin and Zo-1.

\section{Discussion}

Capsaicinoids represent a group of molecules responsible for the spicy taste of hot chili peppers. This group is composed of several molecules, the main ones being capsaicin, dihydrocapsaicin and nordihydrocapsaicin. The pharmacological activity of capsaicin is dependent on the dose and route of administration and is partly mediated by transient receptor potential vanilloid (TRPV) ionchannel receptors. Among the properties of capsaicin are its antiinflammatory, antioxidant and analgesic effects. In human medicine, a beneficial role of capsaicin is reported in pain relief, weight reduction and various cancers [24]. Several studies have shown that capsaicin is rapidly absorbed in the intestine following oral administration [15]. Active transporters do not seem to be involved in this absorption process. However, in rodents, the absorption rates are between $50 \%$ and $95 \%$ depending on the animal models used $[25,26]$. Despite the use of capsaicin as a feed additive for pigs to improve growth and health, no data have been published on its absorption in this species. In the present study, the kinetics of capsaicin transport across epithelial layers were investigated, and its effect on monolayers was explored. Usually, this type of in vitro study is conducted on Caco-2 cells. Caco- 


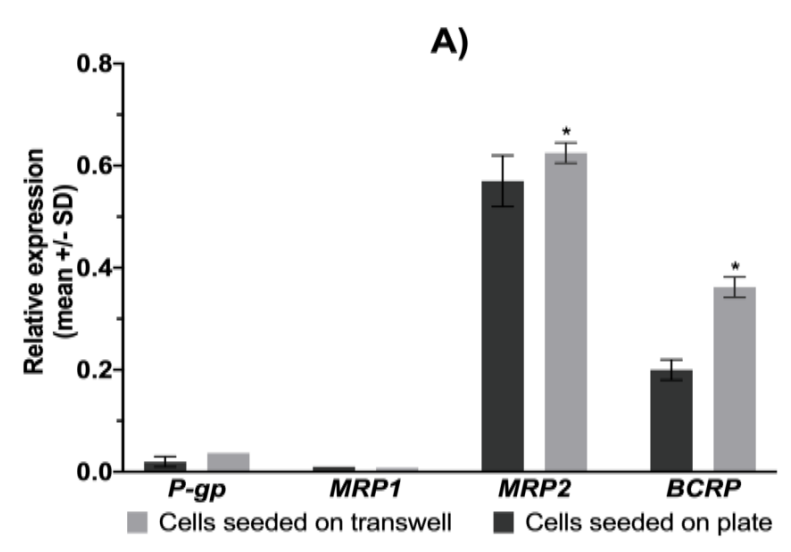

B)
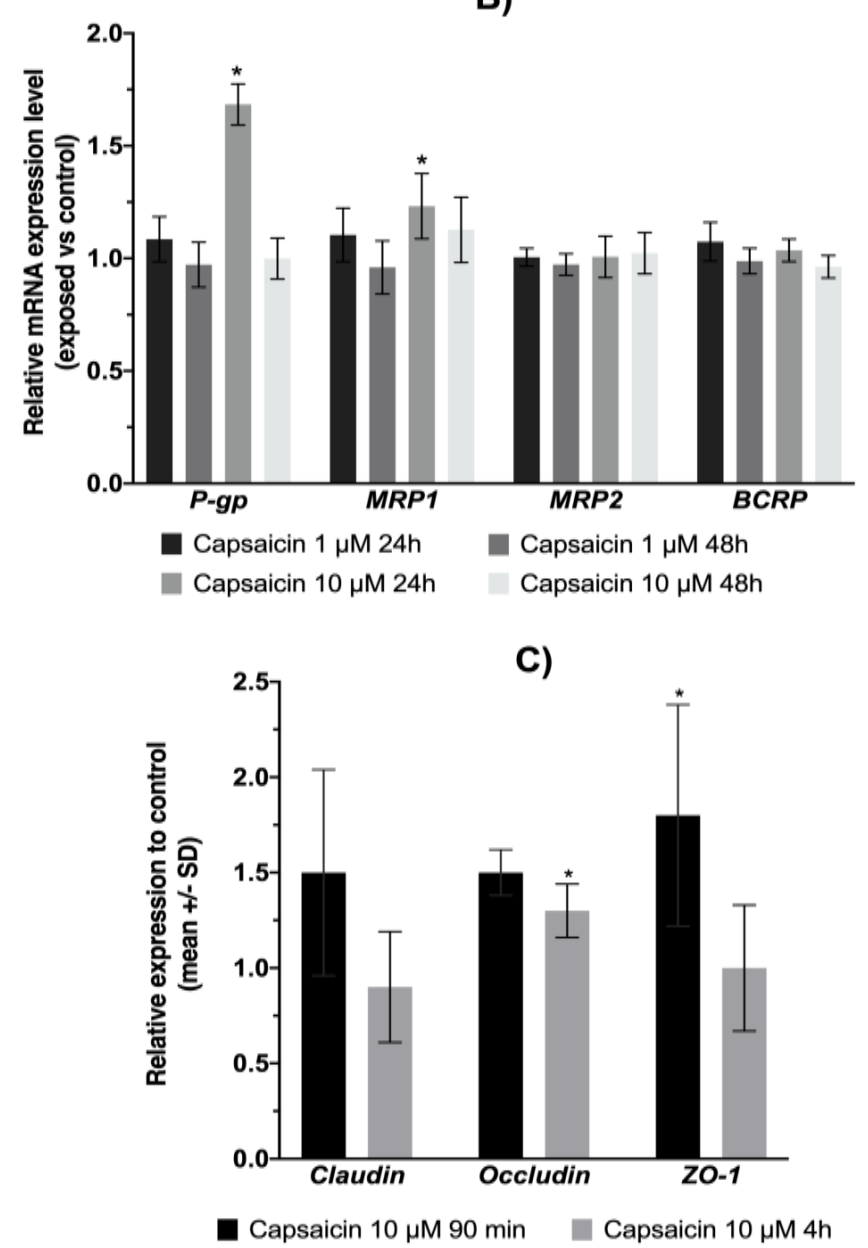

Figure 3: $\mathrm{ABC}$ transporter and tight junction proteins mRNA expression.

A) Expression of the ABC transporter at the mRNA level $(n=4)$. Statistically significantly different from cells seeded on plates, ${ }^{*} \mathrm{p}<0.05$. B) Effect of capsaicin on $\mathrm{ABC}$ transporter mRNA expression in IPEC-J2 cells. The data shown are the means \pm SD from 3 independent experiments. Statistically significantly different from control cells (unexposed), ${ }^{*} \mathrm{p}<0.05$. C) Effect of capsaicin exposure on the mRNA expression level of tight junction proteins. The data shown are the means \pm SD from 3 independent experiments. Statistically significantly different from control cells (unexposed), ${ }^{*} \mathrm{p}<0.05$.

2 cells grown on semipermeable supports are considered a relevant cell model to study passive and active permeability mechanisms at the cellular level [27]. However, it is a cell line from human colon adenocarcinoma. As capsaicin is used in pigs, it is more relevant to use an in vitro model originating from pigs. The IPEC-J2 cell line is a recent nontransformed and nontumorigenic intestinal porcine epithelial cell line. This model is considered a better model because cells maintain their differentiated characteristics and exhibit strong similarities to primary intestinal epithelial cells. Moreover, even if the IPEC-J2 cell line demonstrates functional resemblance to Caco-2 cells, this system is expected to facilitate comparison with the in vivo situation [28].

The IPEC-J2 cell line is a small intestinal porcine epithelial cell line currently used to study porcine intestinal pathogen host interactions, porcine-specific pathogenesis, innate immune responses and alteration of epithelial permeability $[22,29]$. The integrity of the epithelial monolayer is essential to guarantee the absorption of nutrients and ensure organism protection against food contaminants and microbes [30]. Grown on permeable support, cells are intended to differentiate into a single monolayer of polarized enterocytes and express tight junction proteins $[28,31]$. Compared to Caco-2 cells, TEER increases greatly $\left(>1 \mathrm{k} \Omega . \mathrm{cm}^{2}\right)$ with a shorter growing time. The measurement of TEERs is a classically used method to assess the integrity of cellular barrier model systems, especially before evaluation of drug transepithelial transport studies. It is a noninvasive method linked to the ionic conductance of the paracellular pathway in the monolayer [32]. We measured TEER during cell growth, and our results are in accordance with data from the literature [33]. To assess the permeability of the barrier, TEER measurement is associated with the use of paracellular tracer compounds such as fluorescein. This compound is used to detect the contribution of paracellular pathway permeability to Caco-2 cells in vitro models [34,35]. Na-fluorescein is a fluorescent dye with a molecular mass of $376 \mathrm{Da}$ and a complex size of $4.5 \AA$ Ander our conditions, we used sodium fluorescein to assess the effect of capsaicin on the permeability of the epithelium. We observed an intensive transfer of this marker in the absence of capsaicin in IPEC-J2 cells. This is the first time this type of measurement has been performed on IPEC-J2 cells. These results may be explained by the fact that the permeation of this marker is dependent on $\mathrm{pH}$ and an apically located absorptive transporter. This protein is not expressed in Caco-2 cells, as already described by Berginc et al. (2007) [34]. Under our conditions, the transport of fluorescein towards a Caco- 2 cell monolayer was lower than that observed in the IPEC-J2 model, which confirms this hypothesis (data not shown). Expression of a fluorescein transporter needs to be confirmed in IPEC-J2 cells. Despite this first result, transepithelial transfer of fluorescein is significantly increased when the epithelium is exposed to capsaicin for $90 \mathrm{~min}$. This result is in agreement with Tsukura Y. et al.s (2007) [20] study conducted on Caco-2 cells at doses higher than $100 \mu \mathrm{M}$. The authors concluded that permeability is increased by cell death or the formation of large open wounds on the epithelial surface. This result was also confirmed by Isoda $\mathrm{H}$. et al. (2001) [16] with less exposure time to capsaicin at doses from $300 \mu \mathrm{M}$ to $500 \mu \mathrm{M}$. This effect is associated with a decrease of TEER.

The mechanism involved seems to be mediated by the activation of HSP47 and the TRPV1 receptor [16,17]. Nagumo et al. (2007 and 2008) [36,37] also reported that capsaicin induced Ca2+ influx which induced cofilin dephosphorylation and tight-junction opening in 
Caco-2 cells model. In our model, the mRNA expression of TRPV1 was not detected whereas it was expressed in porcine intestine (see supplementary data). Paracellular transfer between enterocytes is limited by tight junctions, and capsaicin $(100 \mu \mathrm{M})$ is able to induce the expression of occludin and claudin-1 proteins [18]. Our results tend to confirm these data, with a slight induction of Occludin mRNA after $4 \mathrm{~h}$ of exposure to capsaicin $10 \mu \mathrm{M}$. Shorter exposure times and lower doses may explain why induction is not truly important. Zo-1 mRNA seems to be more influenced by treatment with capsaicin. The relationship between permeability increase and induction of tight junction protein expression has already been described [38]. Few studies have reported the use of the IPEC-J2 cell line to explore the transfer of xenobiotics compared to the Caco-2 cell model $[39,40]$. Caco- 2 cells express numerous efflux transporters in particular (BCRP and ABCG2) and multidrug resistance-associated proteins (MRPs and ABCCs) in addition to P-gp (ABCC1) [41,42]. These proteins regulate the transcellular pathway through enterocytes of many substrates. BCRP, MRP2 and P-gp are expressed in the apical membrane of enterocytes and reduce oral bioavailability of their substrate, whereas MRP1 is expressed on the basal side [43]. The implication of these proteins in capsaicin transfer through the intestinal epithelium has not yet been considered because of their rapid gastrointestinal absorption demonstrated in vivo. However, the rate of absorption ranges from $50 \%$ to $90 \%$ and has been studied only in rodents or humans. Taking into account species variability and limiting the use of animals, we investigated the kinetics of capsaicin transport across an epithelial layer of IPEC-J2 cells. The results obtained in the IPEC-J2 cell model show that capsaicin easily crossed epithelia with an absorptive $P_{\text {app }}$ higher than $10^{-6} \mathrm{~cm} / \mathrm{s}$, suggesting efficient and complete absorption, as supposed by many authors but not experimentally studied. Duan L. et al. (2018) [44] reported an apparent permeability of $0.80 \times 10^{-6}$ $\mathrm{cm} / \mathrm{s}$ across the jejunal membrane. This value is close to our value obtained with our model. This high permeability is observed at low concentrations, suggesting that active transport is not involved. Moreover, the efflux ratios are not significantly different from 1 . The same results were obtained in a Caco- 2 cell model, which is known to express active transporters. Because the expression of these proteins has not been described in the IPEC-J2 cell line, we investigated their expression at the transcriptomic level. Our results showed that the expression of P-gp and MRP1 was very low compared to the expression of MRP2 and BCRP, even if cells were seeded in transwells. Compared to intestinal expression of $\mathrm{ABC}$ transporter in porcine intestine, MRP1 is greatly expressed whereas other transporters was not detected (see supplementary data). These results confirm the need to develop a transfected model with the MDR1 gene encoding human P-gp [22,45,46]. Finally, as induction of P-gp expression after capsaicin exposure has already been reported, we investigated the influence of capsaicin exposure on the mRNA expression level of $\mathrm{ABC}$ transporters. The induction of P-gp was confirmed at $48 \mathrm{~h}$ under our conditions, even at lower concentrations. This induction was associated with an increase in the mRNA level of MRP1 after 24 $\mathrm{h}$ of exposure to $10 \mu \mathrm{M}$ capsaicin. These results suggest that adding capsaicin to food may have an impact on the absorption of drugs or other nutrients administered at the same time.

\section{Conclusion}

In conclusion, our study showed that a low dose of capsaicin can upregulate the expression of P-glycoprotein and MRP1. The consequences for the activity of these proteins need to be confirmed. In addition, the permeability of capsaicin through the intestinal epithelium is mediated by passive diffusion. As previously observed, capsaicin, even at low doses, may alter the epithelial permeability of the intestinal epithelium.

\section{References}

1. Aarestrup FM (2005) Veterinary drug usage and antimicrobial resistance in bacteria of animal origin. Basic Clin Pharmacol Toxicol 96: 271-281. [crossref]

2. Schwarz S, Kehrenberg C, Walsh TR (2001) Use of antimicrobial agents in veterinary medicine and food animal production. Int J Antimicrob Agents 17: 431-437. [crossref]

3. Chantziaras I, Boyen F, Callens B, Dewulf J (2014) Correlation between veterinary antimicrobial use and antimicrobial resistance in food-producing animals: A report on seven countries. J Antimicrob Chemother 69: 827-834.

4. You Y, Silbergeld EK (2014) Learning from agriculture: Understanding low-dose antimicrobials as drivers of resistome expansion. Front Microbiol 5. [crossref]

5. Van Boeckel TP, Brower C, Gilbert M, Grenfell BT, Levin SA (2015) Global trends in antimicrobial use in food animals. Proceedings of the National Academy of Sciences of the United States of America, 112: 5649-5654.

6. Lillehoj H, Liu H, Calsamiglia S, Fernandez-Miyakawa ME, Chi F, et al. (2018) Phytochemicals as antibiotic alternatives to promote growth and enhance host health. Vet Res 49 .

7. Zeng Z, Zhang S, Wang H, Piao X (2015) Essential oil and aromatic plants as feed additives in non-ruminant nutrition: a review. J Anim Sci Biotech 6. [crossref]

8. Liu Y, Espinosa CD, Abelilla JJ, Casas GA, Lagos LV, et al. (2018) Navarro DMDL, Jaworski NW, Stein, H.H. Non-antibiotic feed additives in diets for pigs: A review. Animal Nutrition 4: 113-125. [crossref]

9. Geiger S, Patra AK, Schrapers KT, Braun HS, Aschenbach JR (2021) Menthol stimulates calcium absorption in the rumen but not in the jejunum of sheep. J Dairy Sci 104: 3067-3081.

10. Dunshea FD, Suster DJ, Kerton, Leury B (2003) A capsaicin analogue improves growth and dressing rate in pigs, particularly gilts. Conference: Australasian Pig Science Association At: Fremantle ed J. Paterson Volume: "Manipulating Pig Production IX" 26.

11. Jarupan T, Rakangthong C, Bunchasak C, Poeikhampha T, Kromkhun P (2018) Effect of Colistin and Liquid Methionine with Capsaicin Supplementation in Diets on Growth Performance and Intestinal Morphology of Nursery Pigs. Int J Pharm Med Biol Sci 7: 46-51.

12. Application of capsaicine for producing pig feed additive.

13. Biggs ME, Kroscher KA, Zhao LD, Zhang Z, Wall EH, Bravo DM, Rhoads RP (2020) Dietary supplementation of artificial sweetener and capsicum oleoresin as a strategy to mitigate the negative consequences of heat stress on pig performance. J Animal Sci 98: 1-12.

14. Leelahuta Y, Glinsukon T, Wangpanish W (1983) In vitro capsaicin metabolism in the rat, mouse and hamster. Toxicon 21: 245-248.

15. Kawada T, Suzuki T, Takahashi M, Iwai K (1984) Gastrointestinal absorption and metabolism of capsaicin and dihydrocapsaicin in rats. Toxicol Applied Pharmacol 72: 449-456. [crossref]

16. Isoda H, Han J, Tominaga M, Maekawa T (2001) Effects of capsaicin on human intestinal cell line Caco-2. Cytotechnology 36: 155-161. [crossref]

17. Han J, Isoda $\mathrm{H}$, Maekawa $\mathrm{T}$ (2002) Analysis of the mechanism of the tight junctional permeability increase by capsaicin treatment on the intestinal Caco-2 cells. Cytotechnology 40: 93-98. [crossref]

18. Uchida R, Han J, Isoda H (2009) Effect of capsaicin on the tight junctional permeability of the human intestinal cells. J Arid Land Studies 19: 89-92. [crossref] 
19. Han Y, Tan TM, Lim LY (2006) Effects of capsaicin on P-gp function and expression in Caco-2 cells. Biochem Pharmacol 71: 1727-1734. [crossref]

20. Tsukura Y, Mori M, Hirotani Y, Ikeda K, Amano F, et al. (2007) Effects of capsaicin on cellular damage and monolayer permeability in human intestinal Caco-2 cells. Biol Pharm Bull;30(10),1982-1986. [crossref]

21. Vergauwen H (2015) The IPEC-J2 cell line. The Impact of Food Bioactives on Health 125-134.

22. Chen Z, Chen H, Li X, Yuan Q, Su J, Yang L, Ning L, Lei H (2019) Fumonisin B1 damages the barrier functions of porcine intestinal epithelial cells in vitro. J Biochem Mol Toxicol 33. [crossref]

23. Ozgür B, Saaby L, Langthaler K, Brodin B (2018) Characterization of the IPEC-J2 MDR1 (iP-gp) cell line as a tool for identification of P-gp substrates. Eur J Pharm Sci;112:112-121. [crossref]

24. Artursson P, Karlsson J (1991) Correlation between oral drug absorption in humans and apparent drug permeability coefficients in human intestinal epithelial (Caco-2) cells. Biochem Biophys Res Commun;175: 880-885. [crossref]

25. Sharma SK, Vij AS, Sharma M (2013) Mechanisms and clinical uses of capsaicin. Eur J Pharmacol 720: 55-62. [crossref]

26. Rollyson WD, Stover CA, Brown KC, Perry HE, Stevenson CD, et al. (2014) Bioavailability of capsaicin and its implications for drug delivery. J Control Release 196: 96-105. [crossref]

27. Suresh D, Srinivasan K (2010) Tissue distribution \& elimination of capsaicin, piperine \& curcumin following oral intake in rats. Ind J Med Res 131: 682-691. [crossref]

28. Volpe DA (2011) Drug-permeability and transporter assays in Caco-2 and MDCK cell lines. Future Med Chem 3: 2063-2077. [crossref]

29. Geens MM, Niewold TA (2011) Optimizing culture conditions of a porcine epithelial cell line IPEC-J2 through a histological and physiological characterization. Cytotechnology 63: 415-423. [crossref]

30. Brosnahan AJ, Brown DR (2012) Porcine IPEC-J2 intestinal epithelial cells in microbiological investigations. Vet Microbiol 156: 229-237. [crossref]

31. Baumgart DC, Dignass AU (2002) Intestinal barrier function. Curr Opin Clin Nutr Metab Care 5: 685-694.

32. He C, Deng J, Hu X, Zhou S, Wu J, et al. (2019) Vitamin A inhibits the action of LPS on intestinal epithelial barrie function and tight junction proteins. Food \& Funct 10: 1235-1242. [crossref]

33. Srinivasan B, Kolli AR, Esch MB, Abaci HE, Shuler ML, et al. (2015) TEER measurement techniques for in vitro barrier model systems. J Lab Autom 20: 107126. [crossref]
34. Zakrzewski SS, Richter JF, Krug SM, Jebautzke B, Lee IM, et al. (2013) Improved cell line IPEC-J2, characterized as a model for porcine jejunal epithelium. PLoS One 8. [crossref]

35. Berginc K, Zakelj S, Levstik S, Ursic L, Kristl A. (2007) Fluorescein transport properties across artificial lipid membranes, Caco-2 cell monolayers and rat jejunum. Eur J Pharm and Biopharm 66: 281-285. [crossref]

36. Molenda N, Urbanova K, Weiser N, Kusche-Vihrog K, Gunzel D, et al. (2014) Paracellular Transport through Healthy and Cystic Fibrosis Bronchial Epithelial Cell Lines - Do We Have a Proper Model?. PLoS ONE 9. [crossref]

37. Nagumo Y, Han J, Bellila A, Isoda H, Tanaka T (2008) Colifin mediates tight-junction opening by redistributing actin and tight-junction proteins. Biochem Biophys Res Comm 377: 921-925. [crossref]

38. Nagumo Y, Han, J, Arimoto M, Isoda H, Tanaka, T (2007) Capsaicin induces colifin dephosphorylation in human intestinal cells. The triggering role of colifin in tight junction signaling. Biochem Biophys Res Comms 355: 520-525. [crossref]

39. Wang Y, Mumm JB, Herbst R, Kolbeck R, Wang Y (2017) IL-22 Increases Permeability of Intestinal Epithelial Tight Junctions by Enhancing Claudin-2 Expression. J Immunol;199: 3316-3325. [crossref]

40. Pisal DS, Yellepeddi VK, Kumar A, Palakurthi S (2008) Transport of Surface Engineered Polyamidoamine (PAMAM) Dendrimers Across IPEC-J2 Cell Monolayers. Drug Delivery 15: 515-522. [crossref]

41. Devreese M, Pasmans F, De Backer P, Croubels S (2013) An in vitro model using the IPEC-J2 cell line for efficacy and drug interaction testing of mycotoxin detoxifying agents. Toxicol In Vitro 27: 157-163. [crossref]

42. Elsby R, Surry DD, Smith VN, Gray AG (2008) Validation and application of Caco-2 assays for the in vitro evaluation of development candidate drugs as substrates or inhibitors of P-glycoprotein to support regulatory submissions. Xenobiotica 38: 11401164. [crossref]

43. Taipalensuu J, Törnblom H, Lindberg G, Einarsson C, Sjöqvist F, et al. (2001) Correlation of Gene Expression of Ten Drug Efflux Proteins of the ATP-Binding Cassette Transporter Family in Normal Human Jejunum and in Human Intestinal Epithelial Caco-2 Cell Monolayers. J Pharmacol Exp Ther 299: 164-170. [crossref]

44. Dietrich CG, Geier A, Oude Elferink RPJ (2003) ABC of oral bioavailibility: transporters as gatekeepers in the gut. Gut 52: 1788-1795. [crossref]

45. Duan L, Peng H, Li G, Wang R, Chen Y (2018) Utility of in vitro and in vivo systems for studying the permeability of capsaicin and nonivamide through different intestinal regions. Xenobiotica 48: 541-545. [crossref]

46. Saaby L, Cederberg Helms HC, Brodin B (2016) IPEC-J2 MDR1, a novel highresistance cell line with functional expression of human P-glycoprotein (ABCB1) for drug screening studies. Mol Pharm 13: 640-652. [crossref]

\section{Citation:}

Espana B, Le Guern D, Rozier C, Prouillac C (2021) Effect of Capsaicin on the Barrier Functions of Porcine Intestinal Epithelial Cells (IPEC-J2). J Pharmacol Pharm Res Volume 4(4): 1-7. 